\title{
QUEEN'S
UNIVERSITY
BELFAST
}

\section{Phylogenetic divergence within the Arcellinida (Amoebozoa) is congruent with test size and metabolism type.}

Macumber, A., Blandenier, Q., Todorov, M., Duckert, C., Lara, E., Lahr, D., Mitchell, E., \& Roe, H. (2019).

Phylogenetic divergence within the Arcellinida (Amoebozoa) is congruent with test size and metabolism type. European Journal of Protistology. https://doi.org/10.1016/j.ejop.2019.125645

\section{Published in:}

European Journal of Protistology

\section{Document Version:}

Peer reviewed version

Queen's University Belfast - Research Portal:

Link to publication record in Queen's University Belfast Research Portal

\section{Publisher rights}

Copyright 2019 Elsevier.

This manuscript is distributed under a Creative Commons Attribution-NonCommercial-NoDerivs License

(https://creativecommons.org/licenses/by-nc-nd/4.0/), which permits distribution and reproduction for non-commercial purposes, provided the author and source are cited.

\section{General rights}

Copyright for the publications made accessible via the Queen's University Belfast Research Portal is retained by the author(s) and / or other copyright owners and it is a condition of accessing these publications that users recognise and abide by the legal requirements associated with these rights.

Take down policy

The Research Portal is Queen's institutional repository that provides access to Queen's research output. Every effort has been made to ensure that content in the Research Portal does not infringe any person's rights, or applicable UK laws. If you discover content in the Research Portal that you believe breaches copyright or violates any law, please contact openaccess@qub.ac.uk. 
Title:

2

3

4

5

Phylogenetic divergence within the Arcellinida (Amoebozoa) is congruent with test size and metabolism type

\section{Author Names:}

Andrew L. Macumber ${ }^{\mathrm{a}}$, Quentin Blandenier ${ }^{\mathrm{b}, \mathrm{c}}$, Milcho Todorov ${ }^{\mathrm{d}}$, Clément Duckert ${ }^{\mathrm{b}}$, Enrique Lara ${ }^{\mathrm{c}}$, Daniel J.G. Lahr ${ }^{\mathrm{e}}$, Edward A.D. Mitchell ${ }^{\mathrm{b}, \mathrm{f}}$ and Helen M. Roe ${ }^{\mathrm{a}}$

\section{Author Addresses:}

a: School of Natural and Built Environment, Queen's University Belfast, Belfast, BT7 1NN, United Kingdom

b: Laboratory of Soil Biodiversity, University of Neuchâtel, Neuchâtel, 2000, Switzerland

c: Real Jardin Botánico de Madrid, Spanish National Research Council, Madrid, E-28014, Spain

d: Institute of Biodiversity and Ecosystem Research, Bulgarian Academy of Sciences, Sofia, 1113, Bulgaria

e: Department of Zoology, Institute of Biosciences, University of São Paulo, São Paulo, 05508-090, Brazil

f: Botanical Garden of Neuchâtel, Neuchâtel, 2000, Switzerland

\section{Corresponding Author:}

A. Macumber, School of Natural and Built Environment, Queen's University Belfast, Elmwood Building, Elmwood Avenue, Belfast, BT7 1NN, United Kingdom Telephone number: +1 (613) 700-5268; e-mail: andrew.1.macumber@gmail.com 
Arcellinida (lobose testate amoebae) are abundant and diverse in many ecosystems, especially in moist to aquatic environments. Molecular phylogeny has shown that overall test morphology (e.g., spherical or elongate) is generally conserved in Arcellinida lineages, but the taxonomic value of other traits (e.g., size, ornamentation, mixotrophy/heterotrophy metabolism type) has not been systematically evaluated. Morphological and physiological traits that correspond to genetic differences likely represent adaptive traits of ecological significance. We combined high-resolution phylogenetics (NAD9-NAD7 genes) and advanced morphometrics to assess the phylogenetic signal of morphological traits of a group of elongate Difflugia species (Arcellinida). The phylogenetic analyses revealed two clades which could be reliably separated by test size and the presence/absence of mixotrophy. Differences in test size may reflect trophic level, with smaller organisms occupying lower trophic levels. In addition to having larger tests, elongate mixotrophic Difflugia are characterised by wide, flat bases and an inflation of the lower two thirds of their test. These morphological traits may provide additional volume for endosymbionts and/or increased surface area to aid light transmission. Our results showcase greater diversity within the elongate Difflugia and highlight morphological traits of ecological and evolutionary significance.

\section{Keywords}

Difflugia; Centroid size; Geometric morphometrics; Molecular barcoding; Morphometry; NADH gene complex 
Arcellinida Kent, 1880 are an order of testate (shelled) Amoebozoa, characterized by broad and thick (lobose) pseudopods used for feeding and locomotion. Like other testate amoebae they enclose their cell body within a test, the morphology and composition of which can be used to identify species (Meisterfeld, 2002). Several features make Arcellinida valuable ecological indicators: (1) they occur in great abundances in moist habitats, from forest soils to peatlands to lakes and even brackish waters (Mitchell et al., 2008; Ogden and Hedley, 1980); (2) a relatively fast reproduction rate and a large scope of morphological plasticity within species could result in relatively rapid evolutionary change (Charman, 2001); (3) the tolerance of some taxa to harsh environmental conditions (Pérez-Juárez et al., 2017); (4) the presence of a simple test facilitates identification and has resulted in several key taxonomic publications over two centuries of study (Leclerc, 1815; Mitchell et al., 2008); and (5) they occupy several trophic levels according to their feeding behaviour (i.e., bacterivory, detritivory, predatory and mixotrophy; Jassey et al. 2013). In addition, the excellent preservation potential of their test (Lahr et al., 2019; Mitchell et al., 2008; Swindles and Roe, 2007), especially in Holocene and acidic sediments, means they are an excellent proxy for paleoenvironmental reconstructions.

Poor taxonomy remains a major obstacle for the systematic use of Arcellinida as bioindicators for present and past environmental conditions (Kosakyan et al., 2016). Uncertainty as to the range of phenotypic plasticity - i.e., the natural variation of test morphologies not mirrored by variation in the genomes (Mulot et al., 2017) - lowers taxonomic precision in the Arcellinida. Mulot et al. (2017) demonstrated that test shape and pore numbers varied with environmental conditions in wild and cultured populations of Hyalosphenia papilio Leidy, 1874. Jennings (1916), in an early study of a clonal culture of Difflugia corona (now Netzelia corona (Wallich, 1864) Gomaa et al., 2017), observed a variation in both number and placement of spines that was independent of environmental conditions. Porfírio-Sousa et al. (2017) observed very little variability in the test or aperture diameter in clonal cultures of Arcella intermedia, but found that wild populations occupied a distinct morphometric space compared to clonal populations, corroborating previous studies (Wanner, 1999). Tremendous phenotypic plasticity present in wild Arcellinida populations was illustrated by Bobrov and Mazei (2004). For each species, results of test length and breadth measurements formed diffuse clouds of transitional morphotypes plotting around weak central peaks rather than dense distributions. Thus, differences in test Arcellinida morphology may not be the result of genomic differences, but merely reflect a species' range of phenotypic variability. Notwithstanding this, Jennings (1916) showed that specific traits (e.g., number of spines and aperture crenulations) could be artificially selected across successive generations, possibly highlighting a pathway for speciation (West-Eberhard, 1989).

Speciation events could result from specific morphotypes that have greater success at exploiting a novel niche (parapatric speciation) (Weisse, 2008). One such pathway could be the development of mixotrophy, whereby testate amoeba host symbiotic green algae (Treboyxiophyceae) in their cytoplasmic vacuoles (Gomaa et al., 2014; Lara and Gomaa, 2017). Mixotrophic taxa represent valuable ecological indicators as they signal nutrient poor conditions, especially in peatlands (Jassey et al., 2013). Jassey et al. (2013) demonstrated that species with large body sizes occupied higher trophic levels and consumed many food sources as compared to smaller species that shared low trophic 
levels with more specific food strategies. Thus, morphological changes that correspond to genetic differences could be of ecological relevance. Greater taxonomic precision would lead to more robust ecological inferences.

Over a decade of molecular research (Nikolaev et al., 2005) has demonstrated several morphological features to be reliable predictors of genetic relatedness among the Arcellinida: (1) aperture outline (e.g., circular vs. slit); (2) presence of a neck; (3) shell outline (in both apertural and lateral view); and (4) shell composition (Gomaa et al., 2012; Kosakyan et al., 2016; Lahr et al., 2019). Lahr et al. (2019) presented a phylogenomic reconstruction based on 250 genes, obtained using single-cell transcriptomic techniques, which divided Arcellinida into five infraorders: (1) Sphaerothecina Kosakyan et al., 2016; Longithecina Lahr et al., 2019; Excentrostoma Lahr et al., 2019; Hyalospheniformes Lahr et al., 2019; and Vonustoma Lahr et al., 2019. For the Hyalospheniformes, ongoing molecular research has demonstrated that other test morphological features (e.g., compression, size, girth) can be used to reliably distinguish taxa at the genus and species level and how these features might be related to an organism's autecology. This remains to be done for the other infraorders of Arcellinida, such as Longithecina, containing the family Difflugiidae Wallich, 1864, one of the most diverse and abundant in wild assemblages.

To better define the boundary between baseline phenotypic plasticity and evolutionarily significant morphological differences, we require faster evolving genetic markers that can distinguish at the genus or species level and advanced morphometrics to characterise all features of the Arcellinida test. Blandenier et al. (2017) developed the application of the mitochondrial nicotinamide adenine dinucleotide dehydrogenase gene marker (NADH) to construct Arcellinida molecular phylogenies that could both characterise deep phylogenetic relationships as well as finer (i.e., genus and species level) relationships. They were able to replicate the topology of the small subunit ribosomal gene (18S rRNA) trees but could also discriminate between two isolates of a single species (i.e., Difflugia nodosa (Leidy, 1879) and Difflugia pyriformis Perty, 1849). Previous morphometric analyses used the average measurements $(n=20-30)$ of several Arcellinida test features (e.g., length, breadth, width) to construct "ideal-individuals" (e.g., Wanner, 1999). This approach does not separate size variation from shape variation and these measurements are often correlated since they overlap in what they are measuring (Zelditch et al., 2012). Geometric morphometric analysis provides a detailed summary of morphological variability across the entire specimen with the added benefit of separating size as an independent variable (Adams and Otárola-Castillo, 2013). Shapes are defined by the geometric configuration of landmarks (fixed anatomically definable locations found on all specimens) and by boundary curves drawn between the landmarks. Geometric morphometrics has been applied to paleontological studies (Adams and Otárola-Castillo, 2013), including microfossils (e.g. diatoms; Beszteri et al. 2005) but has yet to be applied to Arcellinida.

By combining high-resolution molecular markers with advanced morphometrics analysis and applying them to Arcellinida with similar test morphologies we aim to further explore the boundary between phenotypic variability and evolutionarily significant morphological differences. We focus on the elongate type difflugiids as they are abundant in lacustrine habitats, and, like most difflugiids, are poorly characterised by current phylogenetic reconstructions. The results will improve ecological inferences based on morphotype assemblages, as a clearer distinction can be made on which morphological features are 
evolutionarily significant and likely represent an important ecological function. This can further be used to better understand the functional ecological role of Arcellinida and give

\section{Material and Methods}

Sample collection and documentation

Difflugia specimens were isolated from Sphagnum mosses on Pirin Mountain (Difflugia acuminata Ehrenberg, 1830) and lacustrine submerged vegetation from Sofia Southern Park Artificial Lake (Difflugia lanceolata Penard, 1890 and Difflugia oblonga Ehrenberg,

\section{Alignment and phylogenetic analyses}

DNA extraction was performed with a thiocyanate guanidinium solution following the protocol of Duckert et al. (2018) adapted from Chomczynski and Sacchi (1987). New sequences of NADH dehydrogenases were obtained with a novel nested PCR protocol using forward and reverse primers developed by Blandenier et al. (2017) (Table 2). The D. acuminata sequence was obtained using the nested PCR product, whereas we cloned the nested PCR product of D. lanceolata and D. oblonga using a PCR2.1 Topo TA cloning vector and transformed into Escherichia coli TOP10' One Shots cells (Invitrogen kit) following the manufacturer's instructions. For all three taxa, the final PCR product was purified using Millipore kit and sent for sequencing with an ABI3730XL DNA sequencer (Applied Biosystems) at Macrogen, Amsterdam, The Netherlands. Sequences were deposited in GenBank with the following accession numbers: MN524965MN524967.

Using BioEdit (Hall, 1999), we aligned the three obtained sequences with NAD sequences of Blandenier et al. (2017) and sequences from other Amoebozoan mitochondrial genomes retrieved on GenBank. In order to obtain a better resolution, the nucleotide sequences were converted into amino acid sequences and the intergenic region was removed (see Appendix B). The root was placed on the Discosea based on the phylogenetic reconstruction of Kang et al. (2017). Phylogenetic reconstructions were conducted using the CIPRES Portal (Miller et al., 2010). We used three distinct phylogenetic reconstruction methods: (1) we built a Maximum Likelihood phylogenetic tree using the RaxML v.8.2.10 algorithm (Stamatakis, 2014) with the JTT $+\Gamma$ model. 
Bootstrapping was stopped after 150 replicates based on MRE bootstrapping criterion; (2) we built a Bayesian phylogenetic tree using MrBayes (Ronquist and Huelsenbeck, 2003) with a GTR+GAMMA+INVARIANT model ran on two independent chains for 200,000 generations sampled every 100 generations resulting in 4,000 trees, of which $25 \%$ were discarded as the burn-in; and (3) parsimony analysis was performed using TNT version 1.1. (Goloboff et al., 2008), running 1,000 bootstrap replicates using the PAM 250 step matrix in a New Technology search allowing sectorial search, ratchet, drift and tree fusing parameters.

\section{Results}

To quantify test size and shape variation we followed a modified geometric morphometric protocol based on MacLeod (2008) and Zelditch et al. (2012). Appendix C Table C.1 provides detailed information on the source of the images used for geometric morphometric analysis. Images were digitised using the "tps" series of software (Rohlf, 2015). To digitise an image, a landmark was placed on the left and right edge of the test aperture and a set of 28 equally spaced semilandmarks were used to outline the tests between landmarks 1 and 2 (Fig. 1). Landmark and semilandmark coordinates underwent a Procrustes superimposition using sliders to align all specimens and isolate size variation as an independent variable (Rohlf, 2015; Zelditch et al., 2012). Size variation is quantified by centroid size, defined as the square root of the sum of squared distances of all the landmarks of an object to their centroid (Fig. 1; MacLeod 2008). The centroid is the center of gravity of an object obtained by averaging the $\mathrm{x}$ and $\mathrm{y}$ coordinates of all landmarks (Fig. 1). We modeled the Arcellinida test shape space using a principal components analysis (PCA) of the Procrustes superimposed landmarks using the "geomorph" R-package (Adams and Otárola-Castillo, 2013). This package was also used to create five shape models along the first principal component (PC1). We used the FIJI distribution of "ImageJ" with the "ObjectJ" plugin to measure test length (mm), width $(\mathrm{mm})$ and aperture width $(\mathrm{mm})$ from scaled Arcellinida test images. Surface area was estimated using the equation for the surface area of an ellipse.

\section{NADH phylogenetic tree}

We obtained sequences (254-257 bp) of the NAD9-NAD7 genes of $D$. oblonga, $D$. acuminata and D. lanceolata (Fig. 1 and Table 1). The sequence of $D$. oblonga possesses a short intergenic region (indel of $6 \mathrm{bp}$ ), whereas the sequences of $D$. acuminata and $D$. lanceolata possess an overlap of $1 \mathrm{bp}$ as described for Arcella sequences in Blandenier et al. (2017). The phylogenetic reconstruction (Fig. 2) places the Arcellinida in a single clade (98 bootstrap support (bs)/1.00 posterior probability (pp)). Within Arcellinida, infraorder Sphaerothecina represents a robust clade (93 bs/0.99 pp) and our new sequences plot on two distinct clades. Difflugia lanceolata and D. acuminata form the "Lanceolate" clade (95 bs/0.99 pp) and D. oblonga along with D. nodosa and D. pyriformis comprise the "Pyriform" clade (95 bs/0.99 pp). The node supports for these 
three clades within Arcellinida are too low to make any inferences on their placement and relationship to one another (Fig. 2).

\section{Discussion}

Previous phylogenetic reconstructions of the Arcellinida have either lacked "Pyriform" taxa (Gomaa et al., 2017; Lahr et al., 2019) or "Lanceolate" taxa (Blandenier et al., 2017). The addition of two "Lanceolate" taxa and a third "Pyriform" taxon to the NADH phylogenetic tree allows the molecular comparison of these two morphotypes and reveals significant diverging between them (Fig. 2). Importantly, the test morphologies of both the "Lanceolate" and "Pyriform" taxa are relatively similar, having elongate tests with terminal apertures (Fig. 1). It is thus appropriate to investigate the evolutionary significance of morphological traits other than an elongate test with a terminal rounded aperture. 


\section{NADH phylogenetic tree}

Our NADH phylogenetic tree replicates the global topology of the 18S rRNA phylogenetic reconstruction of Gomaa et al. (2017) and Lahr et al. (2019) and the NADH phylogenetic reconstruction of Blandenier et al. (2017). They all show Arcellinida as monophyletic containing three well resolved infraorders: Sphaerothecina, Hyalospheniformes and Longithecina. Our tree suggests distinct diverging within the Longithecina between a "Lanceolate" clade consisting of $D$. lanceolata and $D$. acuminata, and a "Pyriform" clade that includes D. oblonga, D. nodosa, and $D$. pyriformis.

Our phylogenetic placement of D. oblonga contradicts that of the 18S rRNA reconstructions of Gomaa et al. (2017) and Lahr et al. (2019) that placed it amongst the "Lanceolate" group. It should be noted that the same sequence for D. oblonga was used by both Gomaa et al. (2017) and Lahr et al. (2019). Fig. 3 demonstrates that their specimen of $D$. oblonga is morphologically similar, in both shape and centroid size, to other members of the "Lanceolate" group. Gomaa et al. (2017) first described this specimen as Difflugia parva (Thomas, 1954) Ogden, 1983 but reclassified it as $D$. oblonga (small morphotype) following the recommendations of Mazei and Warren (2014), who indicated $D$. parva as a junior synonym of $D$. oblonga. The similarity in shape and centroid size of $D$. lanceolata, $D$. acuminata and $D$. parva could explain why they group together in the 18s rRNA tree of Gomaa et al. (2017). Thus, we recommend that because of its distinct size, $D$. parva should not be synonymized with $D$. oblonga sensu Mazei and Warren (2014).

If the D. oblonga (small morphotype) sequenced in the $18 \mathrm{~S}$ rRNA phylogenetic reconstructions is in fact $D$. parva, a member of the "Lanceolate" group and a distinct species from $D$. oblonga, this leaves no barcoded taxa from the "Pyriform" clade with the 18S rRNA marker. Mazei and Warren (2014) define D. oblonga as being of similar shape to $D$. pyriformis but being relatively narrower in breadth. Our NADH phylogenetic reconstruction further demonstrates that within the lanceolate to oblong shape range, centroid size may be a more reliable morphological trait than PC1 scores (i.e., shape) in predicting genetic relatedness. Our specimens of $D$. oblonga are distinct in centroid size from members of the "Lanceolate" group and represent an intermediate shape between the Lanceolate" group and D. pyriformis (Fig. 3). Centroid size is also an important characteristic in distinguishing other members of the "Pyriform" clade from the "Lanceolate" clade (Fig. 3). We propose that centroid size is a defining feature in the classification of D. oblonga sensu Mazei and Warren (2014) and differentiating it from other members of the "Lanceolate" group.

There are four remaining difflugiids with $18 \mathrm{~S}$ rRNA sequences, listed in decreasing PC1 score order (Fig. 3): Difflugia compressa Carter, 1864, Difflugia hiraethogii Ogden, 1983, Difflugia bryophila (Penard, 1902) Jung, 1942 and Difflugia bacillariarum Perty, 1849. Difflugia bacillariarum plots within the "Lanceolate" group on Fig. 3 and with the "Lanceolate" group in the 18S rRNA reconstructions (Gomaa et al., 2017; Lahr et al., 2019). Difflugia bryophila has the smallest centroid size and PC1 scores that fall within the oblong shape range, but it is not found within the "Lanceolate" group in the $18 \mathrm{~S}$ rRNA reconstruction (Lahr et al., 2019). Difflugia hiraethogii has a compressed and pyriform shape but a centroid size that falls within "Lanceolate" range and groups along 

(Gomaa et al., 2017; Lahr et al., 2019). Difflugia compressa has a centroid size at the lower end of the "Pyriform" range and a shape like that of D. nodosa. Difflugia compressa groups distinctly, along with $D$. bryophila, from the "Lanceolate" group in the 18S rRNA reconstruction (Lahr et al., 2019). Although D. compressa seems like a candidate for the "Pyriform" clade and thus could place this clade within the 18S rRNA reconstructions; grouping of $D$. compressa with $D$. bryophila in the $18 \mathrm{~S}$ rRNA reconstructions, who do not share similar morphological characteristics, complicates the situation. It might be that other features unite these two taxa. The position of the "Pyriform" clade on 18S rRNA phylogenetic reconstructions remains uncertain and thus members of this clade should be the target of future molecular phylogenies.

\section{Test centroid size and its ecological significance}

Based on the data presented, test centroid size is a more reliable metric in differentiating between the "Lanceolate" and "Pyriform" clades than test shape (Fig. 3). Unlike estimates of biovolume that reduce test shape to an idealized shape (i.e., ellipse; Fournier et al., 2012), centroid size is based on the actual dimensions of the test (i.e., distance of each (semi)landmark from the centroid). Thus, centroid size is likely to be the most precise and accurate method for estimating test surface area and estimating test volume for radially symmetrical tests (i.e., D. lanceolata, D. acuminata, D. pyriformis and D. oblonga; see Appendix D Fig. D.1).

The different test centroid size ranges of the "Lanceolate" and "Pyriform" clades might be related to ecological differences between these clades. Jassey et al. (2013) in their study of the microbial food web from a Sphagnum-peatland demonstrated that taxa with large body sizes, as estimated by test length and biovolume, occupy higher trophic levels with more varied food sources as compared to smaller taxa that occupy lower trophic levels, and have more specific feeding strategies. Coeval changes in test size of multiple taxa have been shown to occur in response to environmental stresses: (1) smaller biovolumes associated with higher temperatures could reflect cellular respiration increasing at a greater rate than oxygen diffusion (Wanner, 1999); (2) reduction in test size in response to warmer climates could be indirectly beneficial, by increasing $\mathrm{CO}_{2}$ access for the Chlorella symbionts in mixotrophic taxa, whose metabolism increases in warmer temperatures (Mulot et al., 2017); (3) Marcisz et al. (2016) observed a decrease in average Arcellinida test size in response to multiple disturbances (e.g., fire and peat farming) in their study of Sphagnum peatlands in Poland. Arcellinida test size is thus a trait of major ecological importance and it is imperative to consider it in future studies of Arcellinida communities. We propose that test centroid size to be the most precise and accurate method (to date) of estimating test size and recommend its utilization.

\section{Mixotrophy}

Mixotrophic taxa represent valuable ecological indicators as they signal nutrient poor conditions in peatlands (Jassey et al., 2013) and perhaps in other environments such as lakes but this has yet to be tested. Penard (1902) observed that mixotrophic specimens could survive dysoxic conditions and lack of nutrition longer than non-mixotrophic specimens and hypothesized that it was due to the inclusions of zoochlorellae. Leidy 
(1879) characterised $D$. pyriformis and D. nodosa as being bright green and full of "chlorophyll grains" and stated that the cells of D. acuminata and D. lanceolata are colourless. The absence of mixotrophy in the "Lanceolate" clade might partly explain the genetic divergence from the "Pyriform" clade.

All members of the "Pyriform" clade share a similar centroid size range (Fig. 3) but, unlike the other members, $D$. oblonga does not house endosymbionts (unpublished observation) making centroid size alone an unreliable metric to define mixotrophic taxa. Within the "Pyriform" clade, the combination of centroid size and test shape (i.e., PC1 scores) can characterise mixotrophic taxa as D. pyriformis and D. nodosa tend to have positive PC1 scores reflecting broader shapes with flatter bases and have greater centroid sizes on average as compared to D. oblonga (Fig. 3 ). In addition, D. nodosa is compressed lateral further helping to distinguish it from both $D$. oblonga and D. nodosa. Other mixotrophic taxa such as Difflugia capreolata Penard, 1902 and Difflugia bidens Penard, 1902 are also characterised by larger average sizes and broad morphologies, with D. bidens being compressed as well (Penard, 1902). There are several small ovoid arcellinid taxa that have been observed to house symbiotic algae: Netzelia gramen (Penard, 1902) Gomaa et al., 2017, Difflugia lobostoma Leidy, 1879, Difflugia labiosa Wailes, 1919, Difflugia urceolata Carter, 1864 and Cucurbitella mespiliformis Penard, 1902. However, the $18 \mathrm{~S}$ rRNA phylogenetic reconstruction shows that these taxa, apart from $D$. urceolata and C. mespiliformis that have yet to be phylogenetically placed, belong to a separate infraorder, namely Sphaerothecina, characterised by ovoid to spherical and hemispherical tests (Gomaa et al., 2017). Based on our results, mixotrophic taxa with elongate tests and terminal apertures (i.e., Longithecina) are characterised by both larger average centroid sizes and broader morphologies, especially in the lower portion of the test. This hypothesis requires further testing through the sequencing of missing members of Longithecina and confirmation with other molecular markers (e.g., SSU, COI). The larger average size of the tests could be the result of the greater amounts of energy provided by the endosymbionts, facilitating increases in test size and growth rate. The broader shapes could provide additional space to house endosymbionts in the cell body. In addition, broadening of the test increases surface area and could also allow for greater transmission of light, with the extreme being compression of the test as seen in $D$. nodosa and D. bidens.

\section{Conclusions}

Our approach of applying fast evolving genetic markers and advanced morphometric analysis to Arcellinida with comparable test morphologies was successful in highlighting ecologically relevant morphological traits, namely centroid size and characterising test morphology for mixotrophic taxa. Moreover, it represents a valuable tool for future taxonomic studies in creating detailed morphological descriptions of the phenotypic range of taxa. We did not erect new taxa names as the inability to anchor the clades within the Arcellinida makes inferences on their taxonomic rank (e.g., genus) uncertain. Our results highlight the importance of test centroid size when studying elongate difflugiids and the need for continued sequencing. A large test size range could be indicative of an organism's ability to exploit several trophic levels or perhaps a range of different species. Mixotrophic elongate difflugiids are characterised by the inflation of the lower portion of 
the test, larger centroid size and in some cases lateral compression. Continued research into the ecological relevance of morphological traits will serve to strengthen ecological inferences, increasing the importance of Arcellinida as environmental proxies.

\section{Author Contributions}

Research design (ALM, QB, CD, EL, DL, HR); Provided samples (MT); Provided research space (EM, HR); Laboratory analyses (ALM, QB); Data analyses (ALM, QB, $\mathrm{CD}, \mathrm{DL}$ ); Wrote manuscript (ALM); All authors contributed to revision.

459

\section{Acknowledgements}

461

462

463

464

465

466

467

468

469

470

471

472

473

474

475
Thanks, are expressed to Molly Baur, Amandine Pillonel and David Singer from the Laboratory of Soil Biodiversity at the University of Neuchâtel, Switzerland, and Sarah Hellyar, School of Biological Sciences, Queen's University Belfast for support with molecular barcoding NADH gene of the Arcellinida. We are grateful to Ferry J. Siemensma for sharing his observations of mixotrophic taxa and insights into Arcellinida taxonomy. This work was supported by a Horizon 2020 Marie Skłodowska-Curie Actions Fellowship awarded by the European Commission [Project Number 703381, 2016-2018]; the Swiss NSF [31003A_163254]; Consejera de Educación, Juventud y Deporte, Comunidad de Madrid "Atracción de Talento Investigador" [2017-T1/AMB-5210]; and a FAPESP/QUB SPRINT grant [2015/50327-1]. 
Adams, D.C., Otárola-Castillo, E., 2013. geomorph: an R package for the collection and analysis of geometric morphometric shape data. Methods Ecol. Evol. 4, 393-399.

Beszteri, B., Ács, É., Medlin, L., 2005. Conventional and geometric morphometric studies of valve ultrastructural variation in two closely related Cyclotella species (Bacillariophyta). Eur. J. Phycol. 40, 89-103.

Blandenier, Q., Lara, E., Mitchell, E.A.D., Alcantara, D.M.C., Siemensma, F.J., Todorov, M., Lahr, D.J.G., 2017. NAD9/NAD7 (mitochondrial nicotinamide adenine dinucleotide dehydrogenase gene) - A new "Holy Grail" phylogenetic and DNA-barcoding marker for Arcellinida (Amoebozoa)? Eur. J. Protistol. 58, 175-186. https://doi.org/10.1016/j.ejop.2016.12.002

Bobrov, A., Mazei, Y., 2004. Morphological Variability of Testate Amoebae (Rhizopoda: Testacealobosea: Testaceafilosea) in Natural Populations. Acta Protozool. 43, 133 146.

Chardez, D., 1967. Difflugia oblonga Ehrenberg et ses variétés. Bull Inst Agron Stat Rech Gembloux New Ser. 2, 589-595.

Charman, D.J., 2001. Biostratigraphic and palaeoenvironmental applications of testate amoebae. Quat. Sci. Rev. 20, 1753-1764. https://doi.org/10.1016/S02773791(01)00036-1

Chomczynski, P., Sacchi, N., 1987. Single-step method of RNA isolation by acid guanidinium thiocyanate-phenol-chloroform extraction. Anal. Biochem. 162, 156159.

Duckert, C., Blandenier, Q., Kupferschmid, F.A., Kosakyan, A., Mitchell, E.A., Lara, E., Singer, D., 2018. En garde! Redefinition of Nebela militaris (Arcellinida, Hyalospheniidae) and erection of Alabasta gen. nov. Eur. J. Protistol. 66, 156-165.

Fournier, B., Malysheva, E., Mazei, Y., Moretti, M., Mitchell, E.A.D., 2012. Toward the use of testate amoeba functional traits as indicator of floodplain restoration success. Eur. J. Soil Biol. 49, 85-91. https://doi.org/10.1016/j.ejsobi.2011.05.008

Goloboff, P.A., Farris, J.S., Nixon, K.C., 2008. TNT, a free program for phylogenetic analysis. Cladistics 24, 774-786.

Gomaa, F., Kosakyan, A., Heger, T.J., Corsaro, D., Mitchell, E.A.D., Lara, E., 2014. One Alga to Rule them All: Unrelated Mixotrophic Testate Amoebae (Amoebozoa, Rhizaria and Stramenopiles) Share the Same Symbiont (Trebouxiophyceae). Protist 165, 161-176. https://doi.org/10.1016/j.protis.2014.01.002

Gomaa, F., Lahr, D.J.G., Todorov, M., Li, J., Lara, E., 2017. A contribution to the phylogeny of agglutinating Arcellinida (Amoebozoa) based on SSU rRNA gene sequences. Eur. J. Protistol. 59, 99-107. https://doi.org/10.1016/j.ejop.2017.03.005

Gomaa, F., Todorov, M., Heger, T.J., Mitchell, E.A.D., Lara, E., 2012. SSU rRNA Phylogeny of Arcellinida (Amoebozoa) Reveals that the Largest Arcellinid Genus, Difflugia Leclerc 1815, is not Monophyletic. Protist 163, 389-399. https://doi.org/10.1016/j.protis.2011.12.001

Hall, T.A., 1999. BioEdit: a user-friendly biological sequence alignment editor and analysis program for Windows 95/98/NT, in: Nucleic Acids Symposium Series. [London]: Information Retrieval Ltd., c1979-c2000., pp. 95-98.

Jassey, V.E.J., Meyer, C., Dupuy, C., Bernard, N., Mitchell, E.A.D., Toussaint, M.-L., Metian, M., Chatelain, A.P., Gilbert, D., 2013. To What Extent Do Food Preferences Explain the Trophic Position of Heterotrophic and Mixotrophic Microbial Consumers in a Sphagnum Peatland? Microb. Ecol. 66, 571-580. https://doi.org/10.1007/s00248013-0262-8 
Jennings, H.S., 1916. Heredity, variation and the results of selection in the uniparental reproduction of Difflugia corona. Genetics 1, 407.

Kang, S., Tice, A.K., Spiegel, F.W., Silberman, J.D., Pánek, T., Čepička, I., Kostka, M., Kosakyan, A., Alcântara, D.M.C., Roger, A.J., Shadwick, L.L., Smirnov, A., Kudryavtsev, A., Lahr, D.J.G., Brown, M.W., 2017. Between a Pod and a Hard Test: The Deep Evolution of Amoebae. Mol. Biol. Evol. 34, 2258-2270. https://doi.org/10.1093/molbev/msx162

Kosakyan, A., Gomaa, F., Lara, E., Lahr, D.J.G., 2016. Current and future perspectives on the systematics, taxonomy and nomenclature of testate amoebae. Eur. J. Protistol. 55, 105-117. https://doi.org/10.1016/j.ejop.2016.02.001

Lahr, D.J.G., Kosakyan, A., Lara, E., Mitchell, E.A.D., Morais, L., Porfírio-Sousa, A.L., Ribeiro, G.M., Tice, A.K., Panek, T., Kang, S., 2019. Phylogenomics and Morphological Reconstruction of Arcellinida Testate Amoebae Highlight Diversity of Microbial Eukaryotes in the Neoproterozoic. Curr. Biol. 29, 1-11. https://doi.org/10.1016/j.cub.2019.01.078

Lara, E., Gomaa, F., 2017. Chapter 13: Symbiosis between Testate Amoebae and Photosynthetic Organisms, in: Algal and Cyanobacteria Symbioses. World Scientific, pp. 399-419.

Leclerc, L., 1815. Note sur la Difflugie, nouveau genre de polype amorphe. Memoires Paris Mus. Hist. Nat. 2, 474-479.

Leidy, J., 1879. Fresh-water rhizopods of North America. Government Printing Office, Washington.

MacLeod, N., 2008. PalaeoMaths 101 | The Palaeontological Association [WWW Document]. URL https://www.palass.org/publications/newsletter/palaeomath-101/ (accessed 11.12.18).

Marcisz, K., Colombaroli, D., Jassey, V.E.J., Tinner, W., Kołaczek, P., Gałka, M., Karpińska-Kołaczek, M., Słowiński, M., Lamentowicz, M., 2016. A novel testate amoebae trait-based approach to infer environmental disturbance in Sphagnum peatlands. Sci. Rep. 6. https://doi.org/10.1038/srep33907

Mazei, Y., Warren, A., 2014. A survey of the testate amoeba genus Difflugia Leclerc, 1815 based on specimens in the E. Penard and C.G. Ogden collections of the Natural History Museum, London. Part 2: Species with shells that are pyriform or elongate. Protistology 8, 133-171.

Meisterfeld, R., 2002. Order Arcellinida Kent, 1880, in: Lee, J.J., Leedale, G.F., Bradbury, F. (Eds.), The Illustrated Guide to the Protozoa. Society of Protozoologists, Lawrence, Kansas, USA, pp. 827-860.

Miller, M.A., Pfeiffer, W., Schwartz, T., 2010. Creating the CIPRES Science Gateway for inference of large phylogenetic trees, in: Gateway Computing Environments Workshop (GCE), 2010. Ieee, pp. 1-8.

Mitchell, E.A.D., Charman, D.J., Warner, B.G., 2008. Testate amoebae analysis in ecological and paleoecological studies of wetlands: past, present and future. Biodivers. Conserv. 17, 2115-2137. https://doi.org/10.1007/s10531-007-9221-3

Mulot, M., Marcisz, K., Grandgirard, L., Lara, E., Kosakyan, A., Robroek, B.J., Lamentowicz, M., Payne, R.J., Mitchell, E.A., 2017. Genetic determinism vs. phenotypic plasticity in protist morphology. J. Eukaryot. Microbiol. 64, 729-739.

Nikolaev, S.I., Mitchell, E.A.D., Petrov, N.B., Berney, C., Fahrni, J., Pawlowski, J., 2005. The Testate Lobose Amoebae (Order Arcellinida Kent, 1880) Finally Find their Home within Amoebozoa. Protist 156, 191-202. https://doi.org/10.1016/j.protis.2005.03.002 Ogden, C.G., 1983. Observations on the systematics of the genus Difflugia in Britain (Rhizopoda, Protozoa). British Museum (Natural History). 
Ogden, C.G., 1980. Notes on some Difflugiidae from Norfolk (Rhizopodea, Protozoa). Bull Brit Mus Nat Hist Zool 39, 125-138.

Ogden, C.G., 1979. Comparative morphology of some pyriform species of Difflugia (Rhizopoda). Arch. Für Protistenkd. 122, 143-153.

Ogden, G.G., Hedley, R.H., 1980. An Atlas of Freshwater Testate Amoebae: Soil Sci. 130, 176. https://doi.org/10.1097/00010694-198009000-00013

Penard, E., 1902. Faune rhizopodique du bassin du Léman. Geneva.

Pérez-Juárez, H., Serrano-Vázquez, A., Kosakyan, A., Mitchell, E.A.D., Rivera Aguilar, V.M., Lahr, D.J.G., Hernández Moreno, M.M., Cuellar, H.M., Eguiarte, L.E., Lara, E., 2017. Quadrulella texcalense sp. nov. from a Mexican desert: An unexpected new environment for hyalospheniid testate amoebae. Eur. J. Protistol. 61, 253-264. https://doi.org/10.1016/j.ejop.2017.06.008

Porfírio-Sousa, A.L., Ribeiro, G.M., Lahr, D.J.G., 2017. Morphometric and genetic analysis of Arcella intermedia and Arcella intermedia laevis (Amoebozoa, Arcellinida) illuminate phenotypic plasticity in microbial eukaryotes. Eur. J. Protistol. 58, 187194. https://doi.org/10.1016/j.ejop.2016.11.003

Rohlf, F.J., 2015. The tps series of software. Hystrix 26.

Ronquist, F., Huelsenbeck, J.P., 2003. MrBayes 3: Bayesian phylogenetic inference under mixed models. Bioinformatics 19, 1572-1574.

Stamatakis, A., 2014. RAxML version 8: a tool for phylogenetic analysis and post-analysis of large phylogenies. Bioinformatics 30, 1312-1313. https://doi.org/10.1093/bioinformatics/btu033

Swindles, G.T., Roe, H.M., 2007. Examining the dissolution characteristics of testate amoebae (Protozoa: Rhizopoda) in low $\mathrm{pH}$ conditions: Implications for peatland palaeoclimate studies. Palaeogeogr. Palaeoclimatol. Palaeoecol. 252, 486-496. https://doi.org/10.1016/j.palaeo.2007.05.004

Todorov, M., Golemansky, V., Meisterfeld, R., 2010. Is Difflugia nebeloides (Amoebozoa: Arcellinida) really a Difflugia? Re-description and new combination. Acta Zool Bulg 62, 13-20.

Wanner, M., 1999. A review on the variability of testate amoebae: methodological approaches, environmental influences and taxonomical implications. Acta Protozool. $38,15-29$.

Weisse, T., 2008. Distribution and diversity of aquatic protists: an evolutionary and ecological perspective. Biodivers. Conserv. 17, 243-259. https://doi.org/10.1007/s10531-007-9249-4

West-Eberhard, M.J., 1989. Phenotypic Plasticity and the Origins of Diversity. Annu. Rev. Ecol. Syst. 2, 249-278.

Zelditch, M.L., Swiderski, D.L., Sheets, H.D., 2012. Geometric morphometrics for biologists: a primer. Academic Press. 
618

619

620

621

622

623

624

625

626

627

628

629

630

631

632

633

634

635

636

637

638

639

640

641

642

643

644

645

646

647

648

649
Fig. 1. A-D. Scanning electron micrographs of taxa studied: (A) Difflugia oblonga; (B) D. acuminata; (C) D. lanceolata. All images are to scale. (D) Schematic diagram showing geometric morphometric digitization: numbers represent landmarks; small black circles semilandmarks; the white circle is the centroid from which centroid size is derived.

Fig. 2. Maximum likelihood phylogenetic tree of Arcellinida based on NAD9-NAD7 gene sequences. Numbers at the nodes correspond respectively to bootstrap values (bs), posterior probabilities (p.p.), as calculated with Bayesian inference, and parsimony scores (ps) obtained by maximum parsimony analysis. NA values correspond to cases where the topology was diverging between analysis. The tree was rooted with Discosea, as shown by Kang et al. (2017), and new sequences are highlighted in bold.

Fig. 3. A biplot of principal component 1 (PC-1) scores (x-axis) and centroid sizes (yaxis) from geometric morphometric analysis. Specimens are illustrated as coloured (phylogenetic clade) symbols (taxa). PC-1 scores are translated into shape models illustrated along the top of the figure. Larger symbols represent specimens that have been sequenced and the letter reflects where the results were published: B - (Blandenier et al. 2017); G - (Gomaa et al. 2012, 2017); L - (Lahr et al. 2019); M - present study.

Table 1. List of sequenced species, sampling locations and sequence details.

Table 2. Nested PCR protocol.

Table 3. Summary of Procrustes Principal Component Analysis (first 7 of 60 components). 
Appendix A. Taxonomic details for Arcellinida in this study (Table A.1).

654

655

656

Appendix B. Alignment after converting nucleotide sequences to amino acid sequences and the removal of the intergenic region (Table B.1).

660

Appendix C. Details of the images used for morphometric analysis, including results from geometric morphometric analysis and ImageJ analysis (Table C.1).

661

Appendix D. Biplots demonstrating the relationship between test centroid size (x-axis) and test length (mm), test width (mm) and test aperture size (mm) (Fig. D.1). 